\title{
Pulmonary fibrosis and lung cancer: Risk and benefit analysis of pulmonary resection
}

\author{
P. Kumar, FRCS ${ }^{a}$ \\ P. Goldstraw, FRCS \\ K. Yamada, MD \\ A. G. Nicholson, $\mathrm{DM}^{\mathrm{C}}$ \\ A. U. Wells, FRCP \\ D. M. Hansell, FRCR ${ }^{d}$ \\ R. M. duBois, FRCP \\ G. Ladas, FECTS ${ }^{a}$
}

From the Departments of Thoracic Surgery, ${ }^{\mathrm{a}}$ Respiratory Medicine, ${ }^{\mathrm{b}}$ Histopathology, ${ }^{\mathrm{c}}$ and Radiology, ${ }^{\mathrm{d}}$ Royal Brompton Hospital, London, United Kingdom.

Received for publication June 5, 2002; revisions requested July 17, 2002; revisions received July 30, 2002; accepted for publication Sept 17, 2002.

Address for reprints: Mr. P. Goldstraw, FRCS, Department of Thoracic Surgery, Royal Brompton Hospital, Sydney Street, London SW3 6NP, United Kingdom (Email: p.goldstraw@rbh.nthames.nhs.uk).

J Thorac Cardiovasc Surg 2003;125:1321-7

Copyright (C) 2003 by The American Association for Thoracic Surgery

$0022-5223 / 2003 \$ 30.00+0$

doi:10.1016/S0022-5223(03)00028-X
Objective: Pulmonary fibrosis is associated with an increased risk of lung cancer and outcome of surgical resection in this setting is unknown.

Methods: We studied 22 patients (24 operations) with pulmonary fibrosis and non-small cell lung cancer treated between 1991 and 2000 (study group) and compared outcome with 951 other patients (964 operations) treated for non-small cell lung cancer over the same period (control patients).

Results: The two groups did not differ significantly in age (68 vs 65 years), smoking history ( $86 \%$ vs $95 \%$ smokers), forced expiratory volume in 1 second $(2.5 \mathrm{~L} / \mathrm{min}$ vs $2.3 \mathrm{~L} / \mathrm{min})$ or forced vital capacity $(3.2 \mathrm{~L}$ vs $3.7 \mathrm{~L})$, but patients with pulmonary fibrosis were more likely to be male $(72 \%$ vs $58 \%, P<.05)$. The operative mortality was higher in patients with pulmonary fibrosis than in control patients $(17 \% \mathrm{vs}$ $3.1 \%, P<.01)$ and there was a higher procedure-specific mortality in pulmonary fibrosis for pneumonectomy (33\% vs $5.1 \%, P<.01)$ and lobectomy $(12 \%$ vs $2.6 \%$, $P<.01)$. Patients with pulmonary fibrosis had a higher incidence of postoperative lung injury, $(21 \%$ vs $3.7 \%, P<.01)$ and a longer mean hospital stay (17 vs 9 days, $P<.05)$. In patients with pulmonary fibrosis, the actuarial 3-year survival was $54 \%$. There were 11 deaths in the study group, 4 postoperatively (all acute respiratory distress syndrome) and 7 late deaths (metastatic disease, $\mathrm{n}=2$; progressive pulmonary fibrosis, $\mathrm{n}=5$ ). Median follow-up (to death or last review) was 13 months (range, 0-120 months). Five patients developed postoperative acute respiratory distress syndrome and in 4 of these patients this proved to be fatal. Postoperative acute respiratory distress syndrome was associated with lower preoperative total lung carbon monoxide diffusion capacity (median, 58\% vs 70\%, $P=.03$ ) and lower preoperative carbon monoxide diffusion capacity corrected for alveolar volume (median, $48 \%$ vs $58 \%, P=.05$ ) and a higher preoperative composite physiological index (median, 44 vs $33, P=.008$ ). None of the preoperative lung function parameters or operative finding were predictors of late death.

Conclusion: Patients with pulmonary fibrosis undergoing pulmonary resection for non-small cell lung cancer have increased postoperative morbidity and mortality, but an important subgroup has a good long-term outcome. Postoperative acute respiratory distress syndrome is associated with low preoperative gas transfer and a high composite physiological index. Resection of non-small cell lung cancer is appropriate in pulmonary fibrosis, provided that the level of functional impairment is carefully factored into patient selection. 


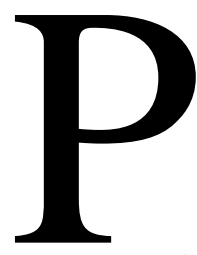

ulmonary fibrosis, also known as fibrosing alveolitis or fibrosing interstitial pneumonia, is a progressive diffuse fibrosing lung disease. Pulmonary fibrosis is associated with an increased risk of lung cancer, with a relative risk of 7.0 to 14.0 (compared to the general population). ${ }^{1,2}$ Furthermore, lung cancer is the cause of death in up to $10 \%$ of patients with pulmonary fibrosis. ${ }^{1}$ However, the operative risks of major pulmonary resection and the long-term survival following resection for nonsmall cell lung cancer in patients with pulmonary fibrosis are unknown.

We reviewed our experience with pulmonary resections for non-small cell lung cancer in patients with pulmonary fibrosis, evaluating the relative operative risks compared to a cohort of patients without pulmonary fibrosis who underwent pulmonary resection for non-small cell lung cancer over the same time period. We then assessed the early and late outcome in patients with pulmonary fibrosis following pulmonary resection and evaluated the predictors for early and late outcome.

The noninvasive assessment of disease severity in pulmonary fibrosis remains debatable. Recently, a composite physiological index (CPI), constructed against the morphological severity of the disease in order to calibrate the quantification of pulmonary fibrosis, has been reported. ${ }^{3}$ CPI correlates more strongly with the extent of disease on computed tomography (CT) than any of the individual pulmonary function tests.

\section{Materials and Methods}

A retrospective review of interstitial lung disease and histopathology registries at the Royal Brompton Hospital was undertaken to identify patients with pulmonary fibrosis who underwent pulmonary resection for non-small cell lung cancer between 1991 and 2000. Histology of the all the pulmonary resections for non-small cell lung cancer was reviewed by a histopathologist specializing in pulmonary pathology (A.G.N.) to identify all the patients with a background of pulmonary fibrosis who had undergone pulmonary resection for non-small cell lung cancer during the study period. We identified 973 patients who underwent 988 pulmonary resections for non-small cell lung cancer. After reviewing the histology of these 988 specimens, 22 patients were identified with evidence of pulmonary fibrosis (Group I), 2 of who underwent 2 operations (24 operations). In the remaining 964 specimens (951 operations) there was no evidence of pulmonary fibrosis (Group II). The patterns of interstitial pneumonia were classified according to recently recognized ATS/ERS criteria ${ }^{4}$ and tumors were classified according to the WHO/IASLC classification system for lung and pleural tumors. ${ }^{5}$

The case records of all patients in both the groups in the study were reviewed retrospectively, with particular reference to preoperative factors likely to predict their outcome. The preoperative CT scans of all 22 patients with pulmonary fibrosis were reviewed by a radiologist specializing in pulmonary diseases (D.H.). We sought to obtain the late outcome only in patients with pulmonary fibrosis, and these patients were contacted and reviewed in the outpatient's clinic to assess their status at follow-up.

\section{Statistical Analysis}

Analyses were performed using STATA software (Stata Data Analysis Software; Computing Resource Centre, Santa Monica, Calif). Group comparisons were made using Wilcoxon's rank-sum test or $\chi^{2}$ testing as appropriate. The prognostic values of age, gender, individual pulmonary function indices, and the CPIs were evaluated using a proportional hazards model.

\section{Pulmonary Function Tests}

The results of preoperative pulmonary function tests were reviewed and recorded with particular reference to forced expiratory volume in 1 second $\left(\mathrm{FEV}_{1}\right)$, forced vital capacity (FVC), total lung capacity, residual volume, carbon monoxide diffusion capacity $\left(\mathrm{DL}_{\mathrm{co}}\right)$, corrected for hemoglobin concentration, and also for alveolar volume $\left(\mathrm{K}_{\mathrm{CO}}\right)$. The results of preoperative arterial blood gas analysis on air were recorded the alveolar-arterial oxygen gradient was calculated.

\section{Calculation of CPI}

The formula for CPI is $91.0-\left(0.65 \times \%\right.$ predicted $\left.\mathrm{DL}_{\mathrm{CO}}\right)-(0.53$ $\times \%$ predicted FVC $)+\left(0.34 \times \%\right.$ predicted $\left.\mathrm{FEV}_{1}\right){ }^{3}$

\section{Preoperative and Operative Protocols}

Preoperative work up for all patients with lung cancer at our institution includes full blood count; biochemical profile; chest radiograph; and a staging CT scan of chest, brain, and abdomen. Bone scans were performed selectively if indicated. All patients had routine arterial blood gas measurement and spirometry. All patients with histologically established pulmonary fibrosis or with impaired spirometry underwent detailed assessment of lung function tests, including assessment of gas transfer factors and a ventilation and perfusion scan to assess the residual pulmonary function postoperatively. All patients over 50 years of age had an electrocardiogram. If there was a history of ischemic heart disease, full cardiological assessment, including a stress test or thallium scan, was performed before proceeding with the pulmonary resection. Medications for pulmonary fibrosis, including steroids and immunosuppressants, were continued throughout the hospitalization for pulmonary resection. Using a double-lumen endotracheal tube, pulmonary resections were performed either through a postero-lateral or lateral muscle-sparing thoracotomy. For most of the operative time the lung was deflated to facilitate dissection, however, while fissures were developed, the lung was temporarily reinflated. At the end of the procedure, the lung was reinflated and examined for air leak prior to closure. Systematic lymph node dissection was performed in all patients undergoing lung resection for accurate intrathoracic staging of lung cancer.

\section{Results \\ Clinical Presentation}

The demographics, clinical features at presentation and the preoperative pulmonary function tests of patients in Groups 
I (pulmonary fibrosis) and II (no pulmonary fibrosis) are summarized in Table 1.

In 12 of $22(54 \%)$ patients in Group I, a diagnosis of pulmonary fibrosis was histologically established prior to resection of the non-small cell lung cancer. These 12 patients were being treated and followed-up at our institution, during which time they developed additional radiographic changes suggestive of a pulmonary malignancy. Seven of 12 underwent further investigations, either fiber optic bronchoscopy or CT-guided biopsy, confirming the presence of non-small cell lung cancer prior to referral for surgery, while in the other 5 patients a definitive diagnosis had not been made prior to thoracotomy. The remaining 10 patients presented with lung cancer without prior recognition of pulmonary fibrosis. This was suspected on the preoperative CT scan but only confirmed histologically after resection. Among these 10 patients, only 5 had a definitive diagnosis of non-small cell lung cancer prior to thoracotomy. Three of 22 patients (13.6\%) had underlying connective tissue disease (systemic lupus erythematosus, $\mathrm{n}=2$; systemic sclerosis, $\mathrm{n}=1$ ). However, it is noteworthy that in all 22 patients, pulmonary fibrosis was evident on the preoperative CT scan.

\section{Pulmonary Resections}

In Group I (patients with pulmonary fibrosis), there were 24 pulmonary resections in 22 patients. Of the 24 pulmonary resections, there were 6 pneumonectomies ( 1 of which was completion pneumonectomy), 17 lobectomies, and 1 localized wedge resection. Two patients underwent pulmonary resections twice. One patient had undergone left upper lobectomy (pT1 N0 M0 adenocarcinoma) and 3 years later was noted to have a further opacity in the left lung field; he subsequently underwent completion pneumonectomy (pT2 N1 M0 squamous cell carcinoma). The second patient had undergone right upper lobectomy (pT2 N0 M0 bronchioalveolar carcinoma) and presented 1 year later with an opacity in the left upper zone, which was treated by a wedge resection (pT1 N2 M0 adenocarcinoma) due to presence of $\mathrm{N} 2$ disease at thoracotomy and impaired lung function.

In Group II, pulmonary resection was performed by pneumonectomy in 215 cases, lobectomy in 695 cases and lesser resection (segmentectomy or wedge resection) in 54 cases.

The distribution of histological cell types of non-small cell lung cancer was similar in the 2 groups.

\section{Relative Risks in Patients with Pulmonary Fibrosis}

Patients with pulmonary fibrosis had a significantly longer mean hospital stay $(17$ vs 9 days, $P<.05)$ and a significantly higher incidence of postoperative acute respiratory distress syndrome/acute lung injury (ARDS/ALI) (21\% vs
TABLE 1. Preoperative clinical details of all patients undergoing pulmonary resection for NSCLC between 1991 and 2000

\begin{tabular}{|c|c|c|c|}
\hline & $\begin{array}{c}\text { Pulmonary } \\
\text { fibrosis }\end{array}$ & $\begin{array}{l}\text { No pulmonary } \\
\text { fibrosis }\end{array}$ & $P$ value \\
\hline Mean age & 68 & 65 & NS \\
\hline Range & 33-87 & $39-85$ & \\
\hline Male & $16 / 22(72)$ & $551 / 951$ (58) & $<.05$ \\
\hline Smokers/ex-smokers & $19 / 22(86)$ & $904 / 951$ (95) & NS \\
\hline $\begin{array}{l}\text { Mean smoking history } \\
\text { (pack-years) }\end{array}$ & 62 & 44 & NS \\
\hline Range & $0-110$ & $0-108$ & \\
\hline Preoperative dyspnea & $11 / 22(50)$ & $*$ & \\
\hline Established diagnosis of FIP & $12 / 22(54)$ & $\mathrm{N} / \mathrm{A}$ & \\
\hline \multicolumn{4}{|l|}{ Pulmonary function test } \\
\hline $\begin{array}{l}\mathrm{FEV}_{1}(\mathrm{~L} / \mathrm{min}) \\
(\% \text { Predicted })\end{array}$ & $\begin{array}{l}2.5 \\
(70)\end{array}$ & $\begin{array}{l}2.6 \\
(57)\end{array}$ & NS \\
\hline Range & $1.4-3.7$ & $1.2-3.9$ & \\
\hline $\begin{array}{l}\text { FVC (L) } \\
\text { (\% Predicted) }\end{array}$ & $\begin{array}{c}3.2 \\
(89)\end{array}$ & $\begin{array}{l}3.5 \\
(80)\end{array}$ & NS \\
\hline Range & $1.6-4.7$ & $1.7-4.9$ & \\
\hline $\mathrm{FEV}_{1} / \mathrm{FVC}$ & 0.78 & 0.73 & NS \\
\hline Range & $0.5-0.88$ & $0.5-0.81$ & \\
\hline $\begin{array}{c}\mathrm{K}_{\mathrm{co}}\left(\mathrm{mmol} \cdot \min ^{-1} .\right. \\
\left.\mathrm{kPa}^{-1} \cdot \mathrm{L}^{-1}\right)\end{array}$ & 0.9 & * & \\
\hline (\% Predicted) & (65) & & \\
\hline Range & $0.66-1.23$ & & \\
\hline $\begin{array}{l}\mathrm{DL}_{\mathrm{co}}\left(\mathrm{mmol} \cdot \mathrm{min}^{-1} .\right. \\
\left.\quad \mathrm{kPa}^{-1}\right)\end{array}$ & 3.9 & $*$ & \\
\hline (\% Predicted) & $(50)$ & & \\
\hline Range & $3.0-5.3$ & & \\
\hline Arterial $\mathrm{P}_{2}$ on air $(\mathrm{kPa})$ & 10.5 & 9.9 & NS \\
\hline Range & $8.5-13.1$ & $8.1-13.2$ & \\
\hline $\begin{array}{l}\% \text { Oxygen saturation } \\
\text { ( } \% \text { on air) }\end{array}$ & 95 & 96 & NS \\
\hline$\%$ On air & $93-98$ & $94-99$ & \\
\hline
\end{tabular}

NS, Not significant; $N / A$, not applicable. Pulmonary function data presented as median values with range. Values in parentheses are percentages.

*Data not available for all patients.

$3.7 \%, P<.01)$. In patients with pulmonary fibrosis the incidence of lung injury ARDS/ALI after pneumonectomy was $33 \%$ compared to $17 \%$ after lobectomy $(P<.05)$.

Compared to the control group, the procedure specific incidence of ARDS/ALI was significantly higher in patients with pulmonary fibrosis for pneumonectomy (33\% vs $6 \%, P$ $<.05)$ and for lobectomy $(17 \%$ vs $3.1 \%, P<.05)$.

Overall postoperative mortality was significantly higher for patients with pulmonary fibrosis $(17 \%$ vs $3.1 \%, P<$ $.01)$. Furthermore, procedure-specific outcome also showed a significantly higher postoperative mortality for pneumonectomy $(33 \%$ vs $5.1 \%, P<.01)$ and lobectomy $(12 \%$ vs $2.6 \%, P<.01)$ in patients with pulmonary fibrosis. There was no difference in the mortality for minor resection $(0 \%$ vs $1.8 \%, P=\mathrm{NS}$ ). 
TABLE 2. Procedure specific mortality and incidence of ARDS/ALI after pulmonary resections for NSCLC between 1991 and 2000

\begin{tabular}{|c|c|c|c|}
\hline & $\begin{array}{c}\text { Group I } \\
\text { Pulmonary fibrosis } \\
(n=24)\end{array}$ & $\begin{array}{c}\text { Group II } \\
\text { No pulmonary } \\
\text { fibrosis } \\
(\mathbf{n}=964)\end{array}$ & $P$ value \\
\hline Mean hospital stay (days) & 17 & 9 & $<.05$ \\
\hline Range & 2-127 & $2-96$ & \\
\hline Total deaths & $4 / 24(17)$ & $30 / 964(3.1)$ & $<.01$ \\
\hline Pneumonectomy & 2/6 (33) & $11 / 215(5.1)$ & $<.01$ \\
\hline Lobectomy & $2 / 17(12)$ & $18 / 695(2.6)$ & $<.01$ \\
\hline Wedge resection & $0 / 1$ & $1 / 54(2.0)$ & NS \\
\hline ARDS/ALI & $5 / 24(21)$ & 36/964 (3.7) & $<.01$ \\
\hline Pneumonectomy & $2 / 6(33)$ & $13 / 215(6)$ & $<.05$ \\
\hline Lobectomy & $3 / 17(17)$ & $22 / 695(3.1)$ & $<.05$ \\
\hline Wedge resection & $0 / 1$ & $1 / 54(1.8)$ & NS \\
\hline
\end{tabular}

NS, Not significant.

Values in parentheses are percentages.

The outcome of all patients that underwent pulmonary resection for non-small cell lung cancer between 1991 and 2000 in summarized in Table 2.

\section{Outcome in Patients with Pulmonary Fibrosis}

Short-term outcome. Morbidity and mortality are detailed in Table 3. Five patients developed postoperative lung injury (ARDS/ALI), as defined by the European/American Consensus Conference, ${ }^{6}$ and 4 of these patients died in the early postoperative period with rapidly progressive ARDS. In terms of procedure-related incidence of ARDS/ALI, 2 of $6(33 \%)$ patients after pneumonectomy and 3 of 17 (17\%) patients after lobectomy developed postoperative ARDS/ ALI. ARDS/ALI was the major postoperative complication.

Postoperative ARDS was associated with lower preoperative $\mathrm{K}_{\mathrm{co}}$ levels (median, $58 \%$ vs $70 \%$; range, $55 \%-67 \%$ vs $44 \%-96 \% ; P=.03$ ), lower preoperative $\mathrm{DL}_{\mathrm{co}}$ levels (median, $48 \%$ vs $58 \%$; range, $42 \%-62 \%$ vs $39 \%-78 \%$; $P=$ .05 ), and a higher preoperative CPI (median, 44 vs 33; range, $37-46$ vs $14-44 ; P=.008$; Wilcoxon rank sum test). A preoperative CPI score $>40$ was associated with a $50 \%$ chance of developing postoperative lung injury. The occurrence of ARDS was not related to demographic features, smoking history, other pulmonary function variables, the presence of preoperative dyspnea, histologically established diagnosis of pulmonary fibrosis before pulmonary resection, the stage of non-small cell lung cancer, or the pattern of inflammation.

Long-term outcome. In patients with pulmonary fibrosis, follow-up ranged from 0.1 to 107 months following surgery, with a mean follow-up 33 months. The overall Kaplan-Meier actuarial survival at 3 years was $54 \%$ (Figure 1). However, only 11 of $22(50 \%)$ patients were alive when last interviewed. There were 7 late deaths during follow-up,
TABLE 3. Morbidity for all patients with pulmonary fibrosis following resection for NSCLC

\begin{tabular}{lc}
\hline $\begin{array}{l}\text { Chest infection (antibiotics and positive } \\
\quad \text { putum culture) }\end{array}$ & $13 / 24(54)$ \\
Prolonged airleak (>2 weeks) & $7 / 24(29)$ \\
ARDS/ALI & $5 / 24(21)$ \\
Cardiac event (myocardial infarction, & $6 / 24(25)$ \\
$\quad$ dysrhythmia) & \\
Neurological event (stroke, transient ischemic attack) & $2 / 24(8)$ \\
$\begin{array}{l}\text { Renal failure (need for renal replacement } \\
\quad \text { therapy) }\end{array}$ & $3 / 24(13)$
\end{tabular}

Data expressed with the total number of operations as the denominator. Values in parentheses are percentages.

including 2 from metastatic lung cancer (both resections staged at IIIA) and 5 from progressive pulmonary fibrosis leading to terminal respiratory failure. The 5 patients that died of progressive pulmonary fibrosis had a median postoperative survival of 14 months (range, 3-36 months). Late mortality was not linked to preoperative pulmonary function indices, the presence of preoperative dyspnea, an histologically established diagnosis of pulmonary fibrosis prior to pulmonary resection, extent of resection, stage of the nonsmall cell lung cancer, or pattern of inflammation.

\section{Histopathology}

Usual interstitial pneumonia (UIP) was present in 16 of 22 patients (15 male and 1 female), with fibrotic nonspecific interstitial pneumonia (NSIP) in the remaining 6 patients (5 female and 1 male). All 3 patients with connective tissue disorders had NSIP. All 4 postoperative deaths and 3 of the 5 late non-neoplastic deaths were associated with UIP.

\section{Evaluation of Preoperative CT Scans}

In order to exclude the possibility that these histological changes of pulmonary fibrosis were a localized obstructive phenomenon related to the tumor and not diffuse parenchymal lung disease, the preoperative CT scan of all 22 patients were reviewed and all showed widespread features consistent with pulmonary fibrosis.

\section{Discussion}

Patients with pulmonary fibrosis have a chronically progressive diffuse fibrosing lung disease. The mean survival from the onset of dyspnea is 3 to 6 years and an objective response to treatment is seen in only $20 \%$ of the cases. ${ }^{7}$ The diagnostic criteria have been recently refined and many patients are now diagnosed on clinical and CT data alone, although most cases, if biopsied, will show a histological pattern of UIP. UIP is the most commonly seen of several recognized patterns of interstitial pneumonia, recognition of which in the context of pulmonary fibrosis provides important prognostic data. NSIP is especially common in those with associated connective tissue disorders. ${ }^{8}$ 
Persistent chronic inflammation with repeated fibrosis has been causally related to the etiology of a variety of neoplasms in various organ systems, including hepatocellular carcinoma in hepatitis $\mathrm{B}$ or $\mathrm{C},{ }^{9}$ gastric cancer in chronic Helicobacter pylori infection, ${ }^{10}$ colonic cancer in longstanding ulcerative colitis, ${ }^{11}$ and pleural lymphoma in longstanding tuberculosis-associated pyothorax. ${ }^{12}$ Using cohort follow-up studies, a higher incidence of lung cancer has been reported in patients with pulmonary fibrosis, with some authors reporting an increased estimated risk of between 7 and 14 times despite adjusting for age, sex, and cigarette smoking. ${ }^{1-2,13}$ However, other authors using a different approach, ie, death certificates registries, have disputed these findings ${ }^{14,15}$ and evidence is currently conflicting. ${ }^{16}$ Nevertheless, independent of relative risk, lung cancer is often seen in patients with chronically established pulmonary fibrosis, ${ }^{1}$ creating a significant surgical problem. This study was undertaken to evaluate the risk and benefit on a cohort of such patients.

Although the role of surgery in the management of non-small cell lung cancer is well established, ${ }^{17,18}$ its value in those patients with underlying pulmonary fibrosis and consequently impaired pulmonary function is unclear.

This study shows that both the operative mortality and morbidity for major pulmonary resection (lobectomy and pneumonectomy) is significantly higher in patients with pulmonary fibrosis. Furthermore, in a subgroup of patients there is an accelerated phase of pulmonary fibrosis leading to respiratory failure following pulmonary resection. Nonetheless, the overall 3-year actuarial disease-free survival of $54 \%$ indicates that pulmonary resection for lung cancer in patients with pulmonary fibrosis is justified if cases are selected appropriately (Figure 1). Patients with pulmonary fibrosis undergoing pulmonary resection, predictors of postoperative ARDS/ALI included preoperative low $\mathrm{K}_{\mathrm{CO}}$, low $\mathrm{DL}_{\mathrm{CO}}$, and high CPI. We did not identify any predictors of long-term survival. When examined more specifically, a prior histological diagnosis of pulmonary fibrosis was not predictive of postoperative ARDS/ALI or late death. Pulmonary fibrosis usually affects the lower lobes. However, the coexisting emphysema preferentially affects the upper lobes. In our study, there were a similar number of upper and lower lobectomies and we were not able to explore the relative importance of disease distribution in this series. A larger cohort will be necessary to explore this further.

The important finding of features of pulmonary fibrosis on the preoperative CT scan suggests that identification of early radiological features of pulmonary fibrosis may be an important marker of increased operative risk.

In this study, we have reported an increased incidence of postoperative respiratory complications, especially ARDS/ ALI as defined by the North American and European Consensus Committee. ${ }^{6}$ All 4 early postoperative deaths follow-

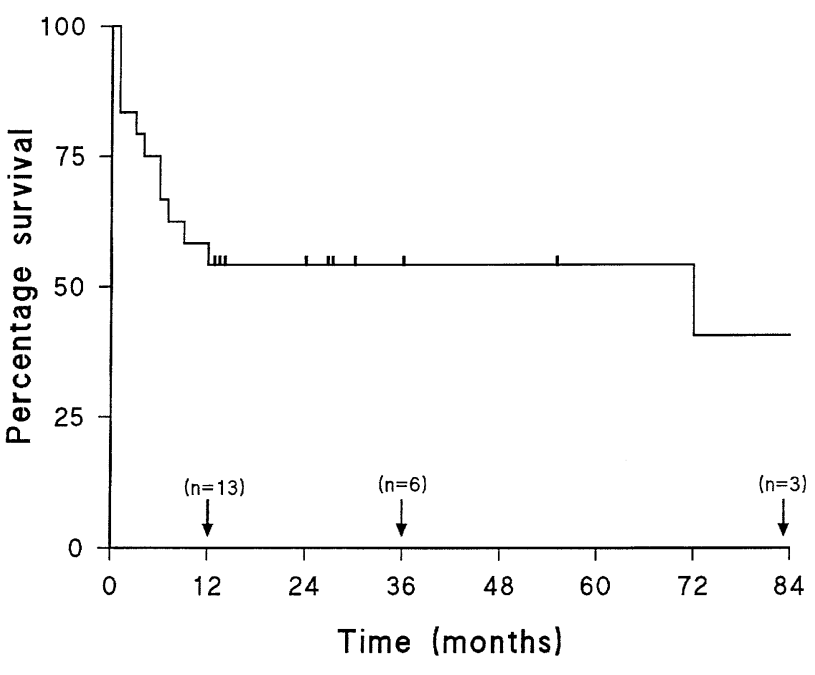

Figure 1. Kaplan-Meier survival curve for all patients with pulmonary fibrosis after pulmonary resection for NSCLC.

ing pulmonary resection were due to rapidly progressive ARDS. We have previously reported the frequency of ARDS/ALI to be $3.9 \%$ following pulmonary resection and more importantly ARDS/ALI to be the cause of $72.5 \%$ of the total mortality after pulmonary resection. ${ }^{19}$ Furthermore, the frequency of ARDS/ALI is directly related to the extent of pulmonary resection, with the incidence of ARDS/ ALI being $3.7 \%$ after lobectomy and $6 \%$ after pneumonectomy. ${ }^{19}$ In this paper, we have reported the overall incidence of ARDS/ALI in patients with pulmonary fibrosis undergoing resection for non-small cell lung cancer to be significantly higher than the incidence of ARDS/ALI in patients with no pulmonary fibrosis undergoing pulmonary resection for non-small cell lung cancer during the same time period ( $21 \%$ vs $3.7 \%$ ). The extent of resection again appears to an important factor, with the incidence of ARDS/ALI for pneumonectomy and lobectomy being $33 \%$ and $17 \%$, respectively. Another identifiable predictor of adverse outcome in patients with pulmonary fibrosis undergoing pulmonary resection for non-small cell lung cancer was the extent of pulmonary resection, the mortality for pneumonectomy being 33\%, compared to $12 \%$ for lobectomy. Therefore, pneumonectomy should ideally be avoided in these patients. However, as the extent of pulmonary resection can only be reliably made intraoperatively after a thorough assessment of intrathoracic lymph node status at thoracotomy, ${ }^{20}$ pneumonectomy may be unavoidable if complete resection is to be achieved. If faced with this scenario, the surgeon may have to opt out of a resection if pneumonectomy is the only possible resection to achieve a complete resection.

The pathophysiology leading to the onset of acute lung injury and ARDS/ALI following pulmonary resection remains unclear and is likely to be multifactorial and possibly 
related to single lung ventilation. ${ }^{21,22}$ It may be that periods of one-lung ventilation needs to be kept to a minimum or avoided completely when undertaking pulmonary resection in patients with pulmonary fibrosis.

In the decision to undertake pulmonary resection in patients with pulmonary fibrosis, a significant concern is the impaired baseline respiratory function due to the underlying pulmonary fibrosis, which will be further compounded by surgical trauma and the adverse effects of general anesthesia. In patients undergoing pulmonary resection, pulmonary function tests have a significant role in the preoperative risk stratification prior to pulmonary resection. ${ }^{23}$

In patients with pulmonary fibrosis, pulmonary function tests are used to monitor disease progression and response to treatment in patients, as well as provide an estimate of the severity of disease. However, in pulmonary fibrosis, the assessment of pulmonary function and the quantification of disease severity are difficult, as it is often confounded by coexisting emphysema. The lowest $\mathrm{K}_{\mathrm{co}}$ in our series was $44 \%$ of predicted in a man who had right upper lobectomy with an $\mathrm{FEV}_{1} / \mathrm{FVC}$ of $2.1 / 3.7=0.57$ and most restrictive $\mathrm{FEV}_{1} / \mathrm{FVC}$ was $1.4 / 1.6=0.88$ with a $\mathrm{K}_{\mathrm{co}} 63 \%$ of predicted in a patient who underwent left upper lobectomy.

Noninvasive assessment of disease severity in pulmonary fibrosis remains debatable. Pulmonary function tests reflect the histological severity of the disease better than the symptoms or chest radiography. Among routine indices, the $\mathrm{DL}_{\mathrm{CO}}$ has the strongest correlation with the morphological extent of the disease, both histologically ${ }^{24}$ and radiologically on $\mathrm{CT}{ }^{25}$ However, the interpretation of pulmonary function tests is confounded by coexisting emphysema, present in over $20 \%$ of the patients and resulting in spurious preservation of lung volumes and depression of gas transfer. ${ }^{26,27}$ Clinico-radiographic-pathologic (CRP) score is derived to a great extent from a combination of 6 lung function variables, ${ }^{27}$ however, the presence of emphysema is not taken into account by the CRP score. Subsequently, the CRP score has been modified to allow for coexisting emphysema but the use of this index relies upon integration of clinical and plain radiographical data. ${ }^{25}$ Recently, a CPI, constructed against the morphological severity of the disease in order to calibrate the quantification of pulmonary fibrosis, has been reported. ${ }^{5}$ CPI correlates more strongly with the extent of disease on CT than any of the individual pulmonary function tests and the better fit of CPI to the extent of disease was ascribable to the correction for confounding effects of emphysema. CPI is also an excellent predictor of prognosis in patients with the UIP form of pulmonary fibrosis. ${ }^{5}$

However, little is known of the value of pulmonary function tests in the context of surgery for patients with pulmonary fibrosis and this study shows that $\mathrm{K}_{\mathrm{CO}}, \mathrm{DL}_{\mathrm{co}}$, and CPI are important preoperative predictors of adverse out- come following pulmonary resection for non-small cell lung cancer. In the study reported here, a preoperative CPI score $>40$ was associated with a $50 \%$ chance of developing postoperative lung injury.

In this study, we also note that progressive pulmonary fibrosis and respiratory failure were an important cause of late death (5/7 late deaths). The cause for this rapidly progressive pulmonary fibrosis following pulmonary resection leading to respiratory failure in patients with pulmonary fibrosis is not known. However, this pattern of disease is described as a terminal event in patients with pulmonary fibrosis ${ }^{28}$ and it may be that surgical trauma and/or general anesthesia accelerates the underlying disease process. Kaplan-Meier survival analysis confirmed an actuarial survival at 36 months to be 54\%. In assessing the longer-term outlook after pulmonary resection for non-small cell lung cancer, the importance of lymph node status and stage of the lung cancer is well recognized. There were inadequate numbers of patients to make any meaningful assessment of lymph node status on survival in this cohort of patients. Eight of 24 (33\%) of the resections were found to have pN1 or $\mathrm{pN} 2$ disease. While looking at the survival figures, it is noteworthy that only 2 of 7 late deaths died of metastatic lung cancer. The other 5 deaths were secondary to progressive pulmonary fibrosis and respiratory failure with a mean postoperative survival of only 14 months (range, 3 months to 3 years). However, this is likely that this reflects death due to progressive pulmonary fibrosis occurring before the clinical manifestation of recurrent or metastatic disease.

We acknowledge that the case series reported here only involves 22 patients with pulmonary fibrosis and as such suffers from the criticisms leveled at all small case series. Indeed, type II errors are theoretically possible when analyzing such small groups. However, as there were no marginal nonsignificant trends, this makes the possibility of type II errors remote when looking at the results of predictors of ARDS following surgery.

In conclusion, we report a significantly higher operative risk (morbidity and mortality) associated with pulmonary resection for non-small cell lung cancer in patients with pulmonary fibrosis. Although knowledge of preexisting pulmonary fibrosis prior to resection was not an important factor in predicting the outcome, the presence of features suggestive of pulmonary fibrosis on the preoperative CT scan should be taken as an important marker for increased operative risk. $\mathrm{K}_{\mathrm{CO}}, \mathrm{DL}_{\mathrm{cO}}$, and CPI are important prognostic indicators. Outcome following pneumonectomy is poor. Following pulmonary resection, there is an accelerated phase of pulmonary fibrosis in some patients. Medium-term outlook for the survivors is favorable and, therefore, pulmonary resection for non-small cell lung cancer in patients with pulmonary fibrosis is justifiable in selected cases. 


\section{References}

1. Turner-Warwick M, Lebowitz M, Burrows B, Johnson A. Cryptogenic fibrosing alveolitis and lung cancer. Thorax. 1980;30:496-9.

2. Hubbard R, Venn A, Lewis S, Britton J. Lung cancer and cryptogenic fibrosing alveolitis. A population based cohort study. Am J Respir Crit Care Med. 2000;161:5-8.

3. Wells AU, Desai SR, Rubens MB, Cramer D, Nicholson AG. Colby TV. Idiopathic pulmonary fibrosis: a composite physiologic index derived from disease extent on computed tomography. Am J Respir Crit Care Med. 2003;167:962-9.

4. Travis WD, King TE, Bateman ED, Lynch DA, Capron LF, Colby TV. ATS/ERS international consensus classification of idiopathic interstitial pneumonias. Am J Respir Crit Care Med. In press.

5. Travis WD, Colby TV, Shimosato Y, Corrin B, Brambilla E, in association with Sobin LH and pathologists from 14 other countries. Histological typing of lung and pleural tumors. In: WHO/IASLC classification of lung and pleural tumors. Berlin: Springer; 1999.

6. Bernard GR, Artigas A, Brigham KL, Carlet J, Falke K, Hudson L, et al. The American-European Consensus Conference on ARDS. Definitions, mechanisms, relevant outcomes and clinical trial co-ordination. Am J Respir Crit Care Med. 1994;149(3 Pt 1):818-24.

7. Nicholson AG, Colby TV, duBois RM, Hansell DM, Wells AU. The prognostic significance of the histologic pattern of interstitial pneumonia in patients presenting with the clinical entity of cryptogenic fibrosing alveolitis. Am J Respir Crit Care Med. 2000;162:2213-7.

8. AU Wells. Lung disease in association with connective tissue disorders. In: Olivieri D, du Bois RM, editors. Interstitial lung diseases. Sheffield: ERS Journals Ltd; 2001. p. 137-64.

9. Manos JP, Walker EM Jr. Viruses and human cancer. Ann Clin Lab Sci. 1983;13:201-6.

10. Wu MS, Shun CT, Lee WC, Chen CJ, Wang HP, Lee WJ, et al. Gastric cancer risk in relation to Helicobacter pylori infection and subtypes of interstitial metaplasia. Br J Cancer. 1998;78:125-8.

11. Lennard-Jones JE, Morson BC, Ritchie JK, Williams CB. Cancer surveillance in ulcerative colitis. Experience over 15 years. Lancet. 1983;2:149-52.

12. Fukayama M, Ibuka T, Hayashi Y, Ooba T, Koike M, Mizutani S. Epstein-Barr virus in pyothorax-associated pleural lymphoma. Am J Pathol. 1993;143:1-7.

13. Stack BHR, Choo-Kang YFJ, Heard BE, Bias WB. The prognosis of cryptogenic fibrosing alveolitis. Thorax. 1972;27:535-42.

14. Wells C, Mannino DM. Pulmonary fibrosis and lung cancer in United
States: analysis of multiple cause of death data, 1979 through 1991. South Med J. 1996;89:505-10.

15. Harris JM, Cullinan P, McDonald JC. Does cryptogeneic fibrosing alveolitis carry an increased risk of death from lung cancer? J Epidemiol Community Health. 1998;52:602-3.

16. Samet JM. Does idiopathic pulmonary fibrosis increase the lung cancer risk? Am J Respir Crit Care Med. 2000;161:1-2.

17. Morrison K, Deeley T, Cleland W. The treatment of carcinoma of the bronchus: a clinical trial to compare surgery and supravoltage radiotherapy. Lancet. 1963;1:683-4.

18. Flehinger BJ, Kimmel M, Melamed MR. The effect of surgical treatment on survival from early lung cancer. Implications for screening. Chest. 101:1013-18.

19. Kutlu CA, Williams EA, Evans TW, Pastorino U, Goldstraw P. Acute lung injury and acute respiratory distress syndrome after pulmonary resection. Ann Thorac Surg. 2000;69:376-80.

20. Graham AN, Chan KJ, Pastorino U, Goldstraw P. Systemic nodal dissection in the intrathoracic staging of patients with non-small cell lung cancer. J Thorac Cardiovasc Surg. 1999;117:246-51.

21. Jordan S, Mitchell JA, Quinlan GJ, Goldstraw P, Evans TW. The pathogenesis of lung injury following pulmonary resection. Eur Respir J. 2000;15:790-9.

22. Williams EA, Quinlain GJ, Anning PB, Goldstraw P, Evans TW. Lung injury following pulmonary resection in the isolated, blood-perfused rat lung. Eur Respir J. 1999;14:745-50.

23. Reilly JJ Jr, Mentzer SJ, Sugarbaker DJ. Preoperative assessment of patients undergoing pulmonary resection. Chest. 1993;103(Suppl 4): S342-5.

24. Cherniack RM, Colby TV, Flint A, Thurlbeck WM, Waldron JA Jr, Ackerson L, et al. Correlation of structure with function in idiopathic pulmonary fibrosis. Am J Respir Crit Care Med. 1995;151:1180-8.

25. Wells AU, King AD, Rubens MB, Cramer D, du Bois RM, Hansell DM. Lone cryptogenic fibrosing alveolitis: a functional-morphological correlation based on extent of disease on thin section computer tomography. Am J Respir Crit Care Med. 1997;155:1367-75.

26. Docherty MJ, Pearson MG, O'Grady EA, et al. Cryptogenic fibrosing alveolitis with preserved lung volumes. Thorax. 1997;52:998-1002.

27. Watters LC, King TE, Schwarz MI, Waldron JA, Stanford RE, Cherniack RM. A clinical, radiographic and physiologic scoring system for the longitudinal assessment of patients with idiopathic pulmonary fibrosis. Am Rev Respir Dis. 1986;133:97-103.

28. Bouros, D, Nicholson AG, Polychronopoulos V, duBois RM. Acute interstitial pneumonia. Eur Respir J. 2000;15:412-8. 